
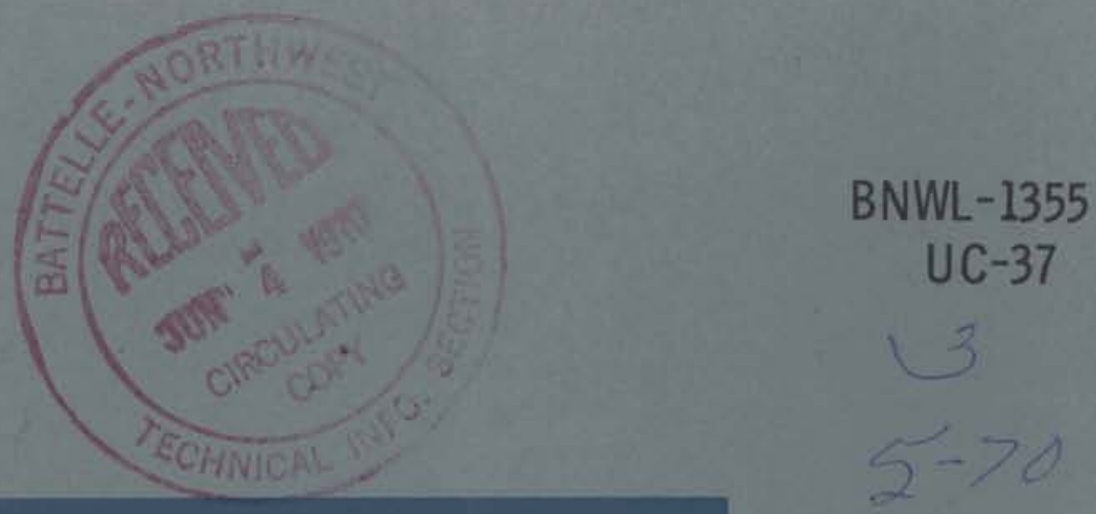

AN EDDY CURRENT TUBE TESTING TECHNIQUE USING A HYBRID COIL CONFIGURATION WITH SEQUENTIAL SAMPLING

J. Ryden, Jr.

May 1970

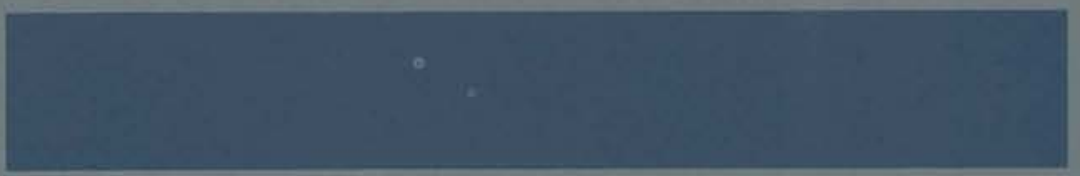

AEC RESEARCH \& DEVELOPMENT REPORT

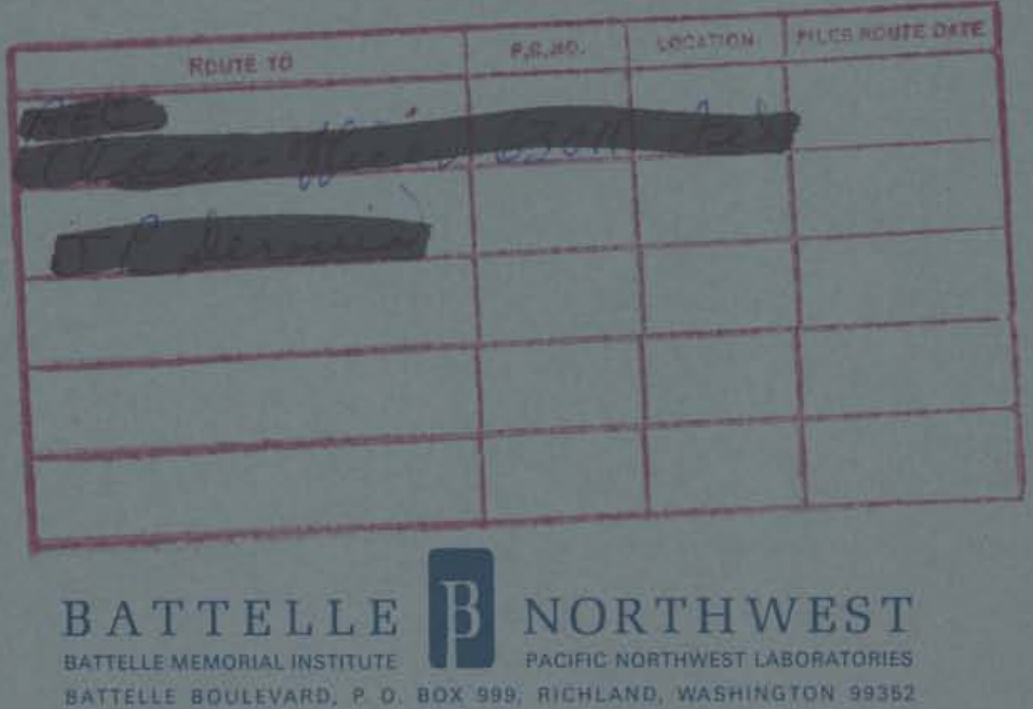




\section{LEGAL NOTICE}

This report was prepared as an account of Government sponsored work. Neither the United States; nor the Commission, nor any person acting on behalf of the Commission:

A. Makes any wartanty or representation, expressed or implied, with respect to the accuracy, completeness, or usefulness of the information contained in this report, or that the use of any information, apparatus; method, or process disclosed in this report may not infringe privately owned rights; or

B. Assumes any liabilities with respect to the use of, or for damages resulting from the use of any information, apparatus, method, or process disclosed in this report.

As used in the above, "person acting on behalf of the Commission" includes any employee or contractor of the Commission, or employee of such contractor, to the extent that such employee or confractor of the Commission, or employee of such contractor prepares, disseminates, or provides access 10; any infarmation pursuant to his employment or contract with the Commission, or his employment with such contractar.

\section{PACIFIC NORTHWEST LABORATORY \\ RICHLAND, WASHINGTON \\ operated by \\ BATTELLE MEMORIAL INSTITUTE \\ for the}

UNITED STATES ATOMIC ENERGY COMMISSION UNDER CONTRACT AT(45.1)-1830

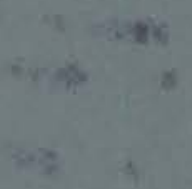


33679000619389

BNWL- 1355

UC- 37 , Instruments

\section{AN EDDY CURRENT TUBE TESTING TECHNIQUE \\ USING A HYBRID COIL CONFIGURATION \\ WITH SEQUENTIAL SAMPLING}

By

J. Ryden, Jr .

Nondestructive Testing Department

Systems and Electronics Division

May 1970

\section{0}

BATTELLE MEMORIAL INSTITUTE

PACIFIC NORTHWEST LABORATORIES

RICHLAND, WASHINGTON 99352 



\title{
AN EDDY CURRENT TUBE TESTING TECHNIQUE \\ USING A HYBRID COIL CONFIGURATION \\ WITH SEQUENTIAL SAMPLING
}

J. Ryden, Jr.

\begin{abstract}
A new eddy current tube testing technique has been deve1oped. This technique has increased resolution and sensitivity to defects and a reduction of nonpertinent tubing variations as compared to the encircling coil technique. This is accomplished with no loss of inspection rate.

The new technique utilizes a hybrid coil configuration consisting of both encircling coils and probe coils. The encircling coils are used as the drivers. A plurality of probe coils, mounted between the encircling coils around the coil form circumference, serve as the pickups. These are sequentially sampled at a rapid rate; thus, a $100 \%$ inspection of the tube is performed by only translating the tube through the coil form.
\end{abstract}




\section{CONTENTS}

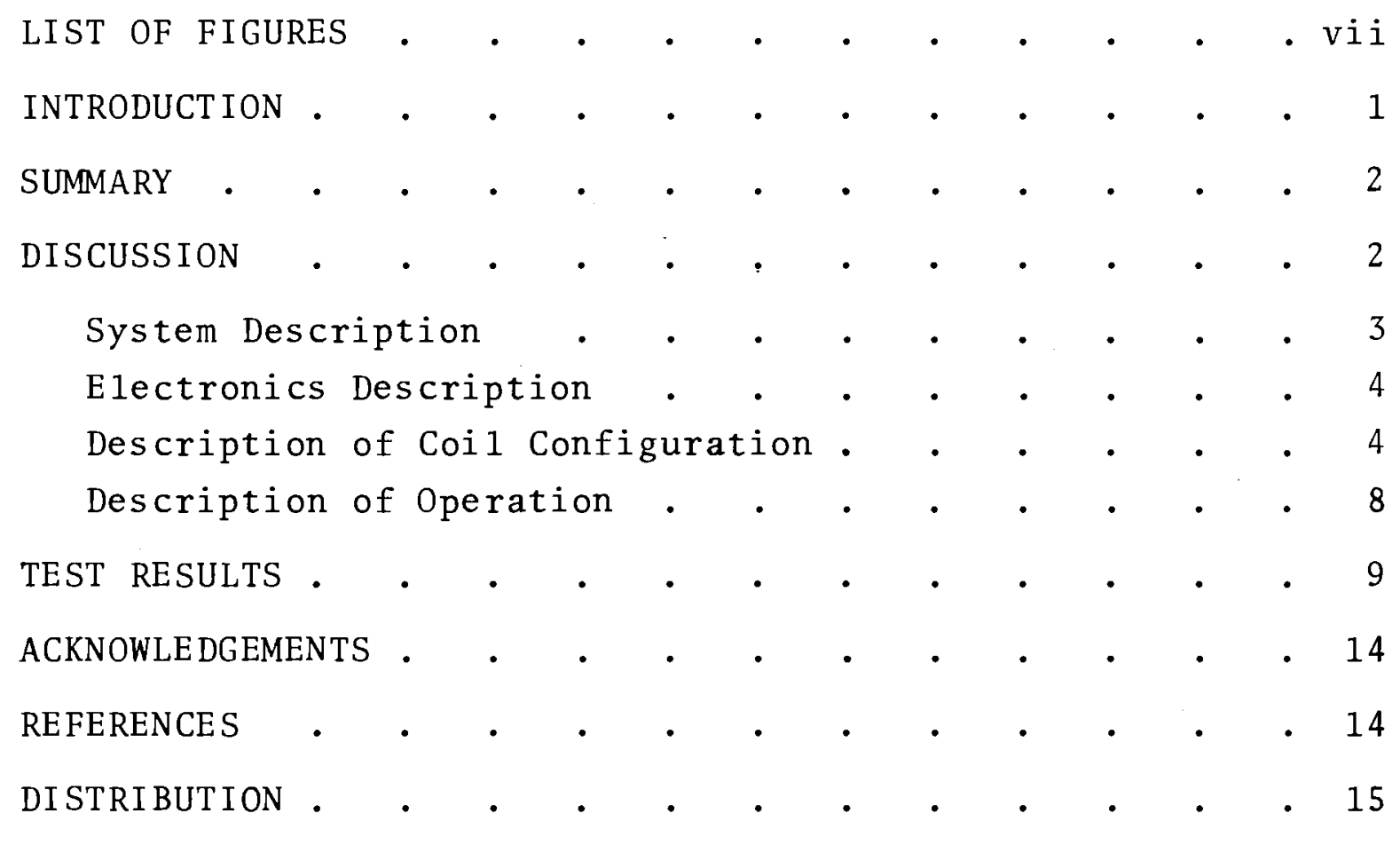




\section{LIST OF FIGURES}

1 Eddy Current Test System 3

Block Diagram of Hybrid Coil Eddy Current
Tester

3 Sketch of Hybrid Coil Form 6

4 Hybrid Coil Form 7

5 Single Probe Coil 7

6 Sketch of 0.230 in. OD Calibration Standard 10

7 Encircling Coil Results, 0.230 in. OD Standard 11

8 Hybrid Coil Results, 0.230 in. OD Standard 11

9 Encircling Coil Results, 0.563 in. OD Standard 13

10 Hybrid Coil Results, 0.563 in. OD Standard 13 
BNWL- 1355

\section{AN EDDY CURRENT TUBE TESTING TECHNIQUE USING A HYBRID COIL CONFIGURATION \\ WITH SEQUENTIAL SAMPLING}

J. Ryden, Jr.

\section{INTRODUCTION}

The increased use of tubing in such critical applications as reactor fuel cladding has imposed a need for improved nondestructive testing. (1) This report describes a new eddy current technique developed by Battelle-Northwest. This eddy current technique has increased resolution and sensitivity to tubing defects over that of the encircling coil method and yet has comparable throughput rates.

The prototype system using this technique operates on a single frequency and utilizes both the in-phase and quadrature components of the test signal.

The coil configuration consists of both encircling coils and a plurality of small diameter probe coils. The two differentially connected encircling coils function as drivers. The probe coils are mounted between the encircling coils around the coil form circumference and function as pickups. These probe coils are sequentially sampled at a high rate. Thus, in effect, the instantaneous inspection area is approximately equivalent to the area of the probe coils being sampled. This area is considerably smaller than that of a conventional encircling coil tester. Therefore, the new tester is less susceptible to nonpertinent signals such as those produced by dimensional variations. Consequently, the sensitivity to localized discontinuities is proportionally increased. 
BNWL -1355

\section{SUMMARY}

A reduction of nonpertinent signals, such as those caused by dimensional variations, and an increase in sensitivity to small defects has been achieved by the development of a new eddy current tube testing technique. The technique utilizes a hybrid coil configuration, sampling of multiple pickup coils and signal phase discrimination to attain these capabilities. A tube is $100 \%$ inspected by only traversing the tube through the bore of the coil form. No rotation of either the coils or the tube is required. Consequently, the throughput rate is comparable to that of a system that uses on ly encircling coils.

\section{DISCUSSION}

One particular problem that eddy current test systems have had to contend with is that the test signals contain too much information. Test specimen parameters such as dimensional variations and material inhomogeneity contribute signals that are in some cases indistinquishable from defect signals. Often when a test is made only for defects, the dimensional and inhomogeneity signals mask out the defect signals. The technique described in this report was developed to increase the sensitivity to defects and to reduce the sensitivity to the other material variations. This was done by decreasing the inspection area through the use of small diameter probe coils as pickups. The necessity for helically scanning the tubing is eliminated by having multiple probe coils. These coils are mounted around the coil form circumference in sufficient numbers to provide $100 \%$ inspection of the tube. By sampling the coils at a high rate, full advantage is obtained from the small inspection area of each coil. 


\section{SYSTEM DESCRIPTION}

The complete prototype eddy current test system is shown in Figure 1. It consists of the electronics section, the tubing transport mechanism and the coils.

The electronics section is comprised of a laboratory eddy current tester modified with switching, gating and some additional balance circuits.

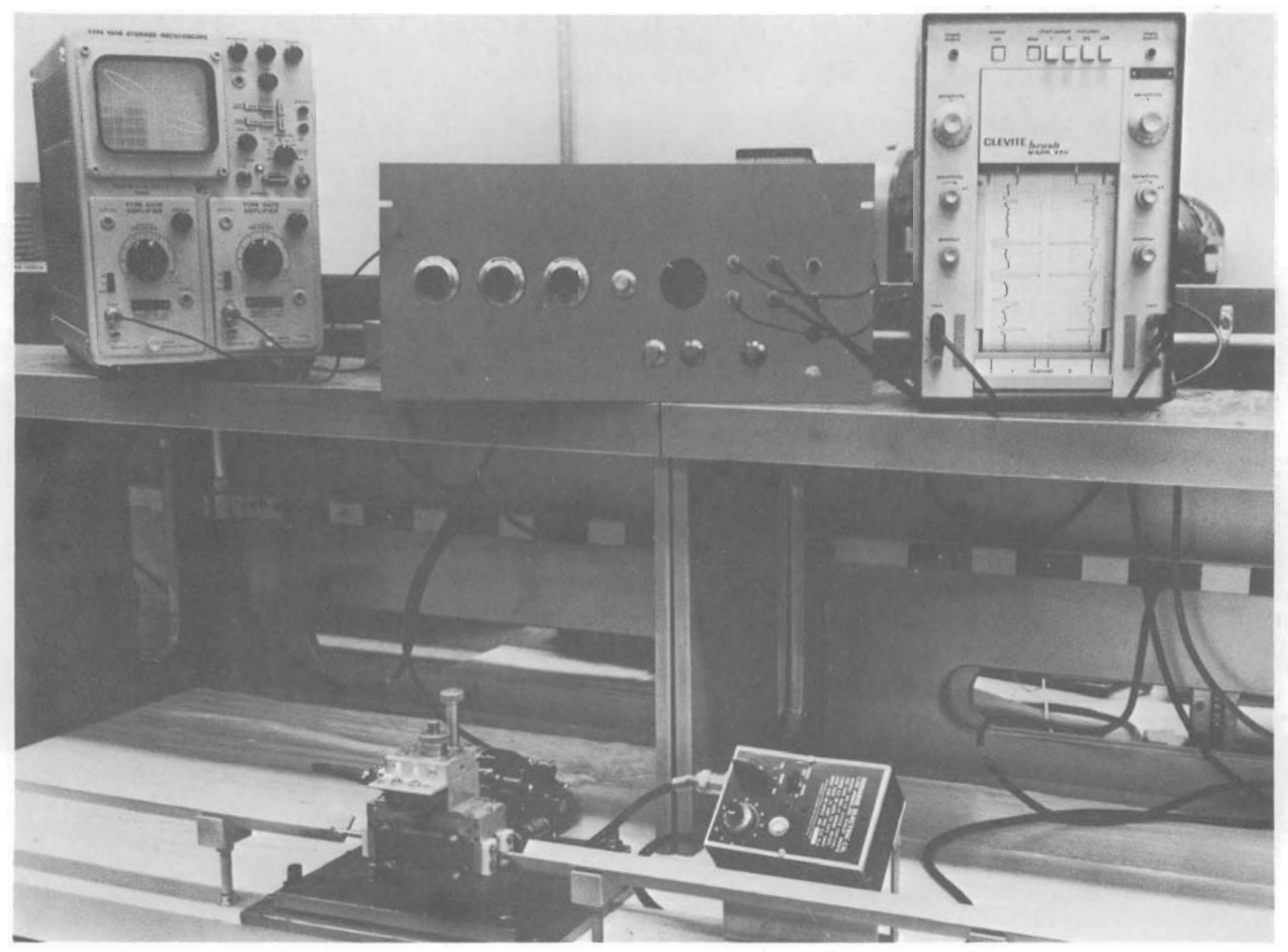

Neg 700650-4

FIGURE 1. Eddy Current Test System 
The tubing transport system provides the required translation of the tubing through the bore of the coil form. Runouts on either side of the drive head support the tubes.

A single coil form contains all of the coils. This coil form is mounted between the drive rollers on the transport device.

\section{ELECTRONICS DESCRIPTION}

A block diagram of the prototypical electronics section is shown in Figure 2. The actual number of some of the circuits, such as signal gates, depends upon the particular application. Therefore, only a general description follows.

The electronics consists of a modified eddy current tester. The principle of operation of the unmodified tester has been explained by Libby ${ }^{(2)}$ and will not be reviewed here.

The modifications added to the tester include timing, switching, gating, null and alarm circuits. The timing clock supplies pulses to the recycling counter at a rate of $10 \mathrm{kHz}$. This binary coded decimal ( $B C D$ ) counter produces the required count. This count is then decoded by the binary-to-decimal decoder. The outputs of this circuit produce a continuing sequence of pulses at a high rate. These pulses are coupled to the signal gates and cause the gates to be sequenced "on" in a continuing manner.

Balance circuits are required for each set of coils being monitored. Controls are provided so that both the amplitude and phase of the balancing voltage can be varied.

\section{DESCRIPTION OF COIL CONFIGURATION}

This technique uses a coil configuration consisting of both encircling coils and probe coils. The dimensions and spacing of all the coils as well as the number of probe coils and their diameters depend upon the size of tube being inspected. 


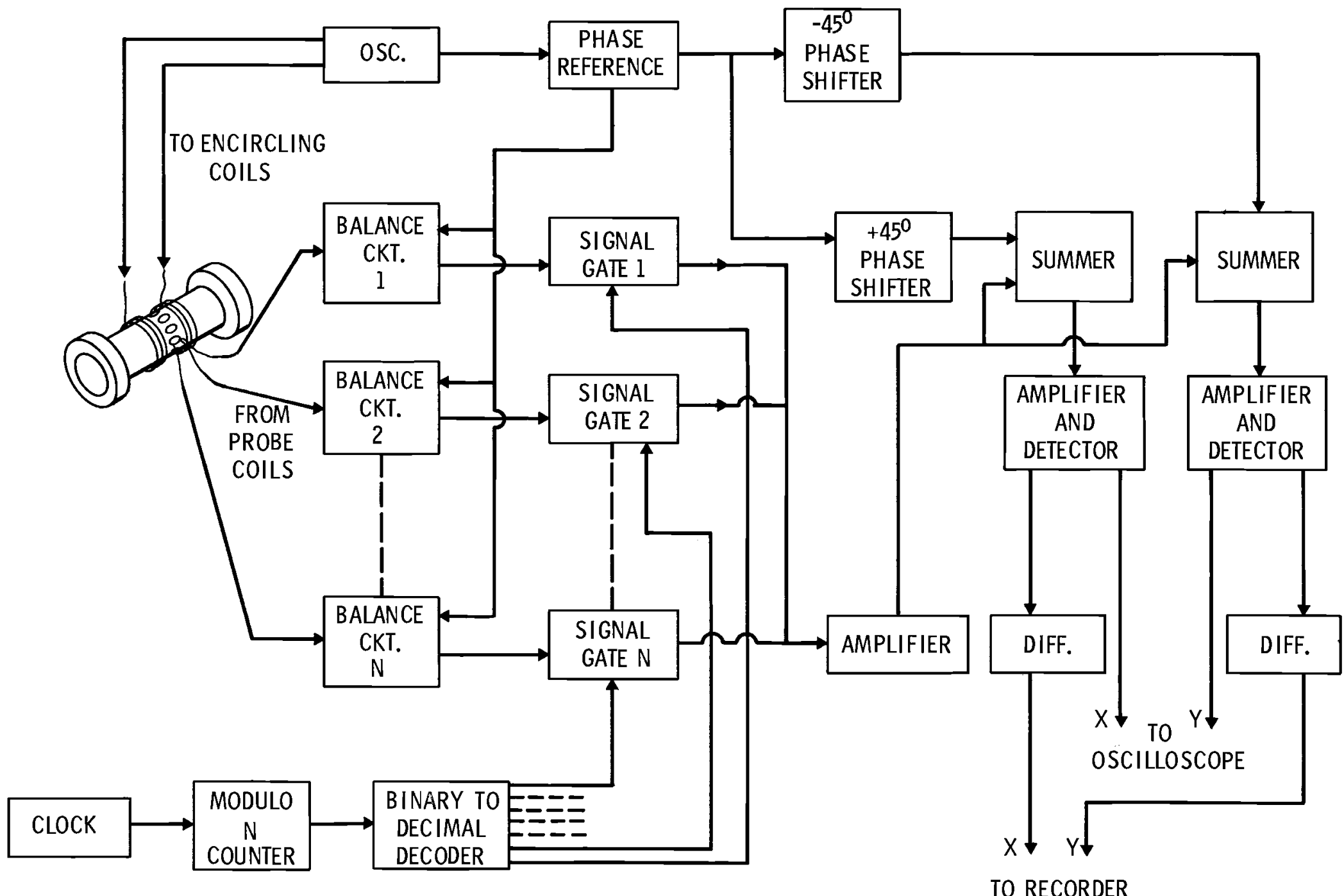

TO RECORDER

FIGURE 2. Block Diagram of Hybrid Coil Eddy Current Tester 
A drawing of the experimental coil form used for 0.230 in. OD tubing is shown in Figure 3. The desired detection level was for defects equivalent in size to a 1 mil deep by $30 \mathrm{mils}$ long electric-discharge-machined notch. Each encircling coil consists of 150 turns of $2.5 \mathrm{mil}$ diameter wire. The coils are wound in two $50-\mathrm{mil}$ wide slots spaced $60 \mathrm{mils}$ apart.
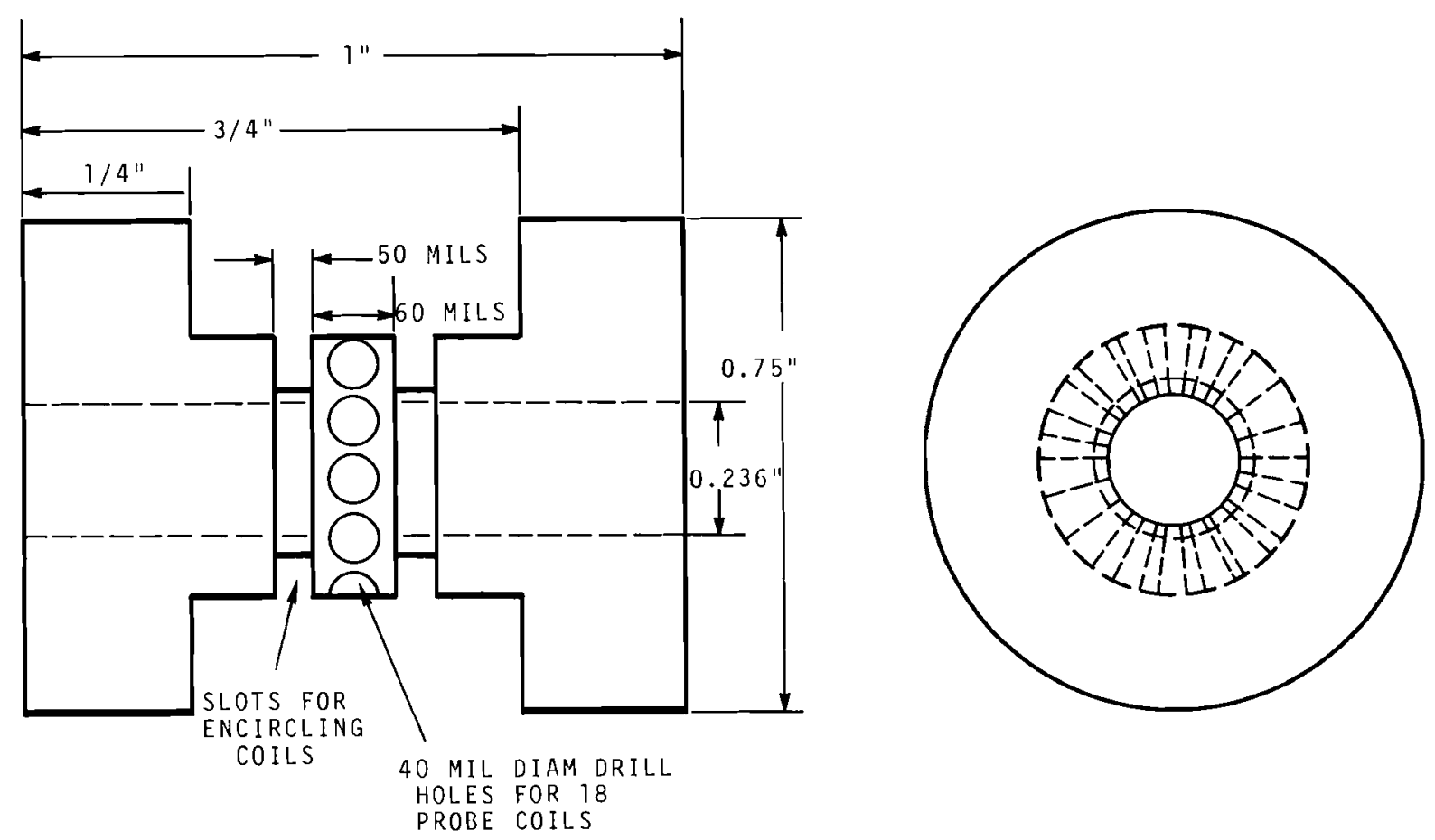

FIGURE 3. Sketch of Hybrid Coil Form

Each probe coil consists of 100 turns of 1.5 -mil diameter wire wound on a number $80 \mathrm{drill}$. The coils are $38 \mathrm{mils}$ in diameter by $30 \mathrm{mils}$ long. These probe coils are mounted in radially drilled holes which are between the encircling coils. A total of 18 coils, spaced 5 mils apart, provide $100 \%$ inspection of the tube circumference. A photograph of the complete coil form is shown in Figure 4. A single probe coil is shown in Figure 5 . 
BNWL- 1355

Neg 700650-3

FIGURE 4. Hybrid Coil Form
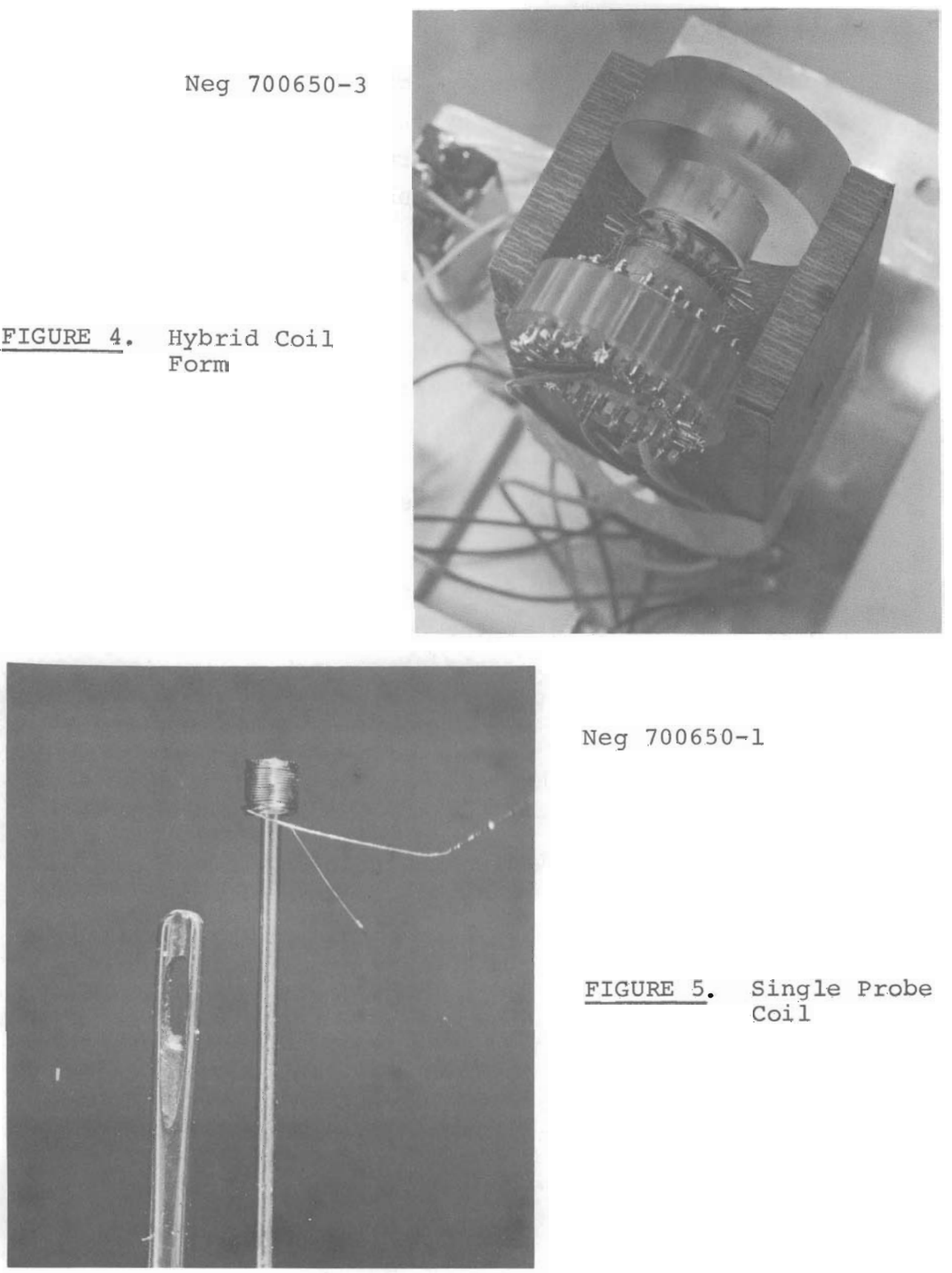

Neg 700650-1

FIGURE 5. Single Probe Coil 
BNWL- 1355

\section{DESCRIPTION OF OPERATION}

The operation of the system is quite straightforward. An alternating current is supplied by the electronics to the encircling coils. These coils in turn produce a magnetic field which induces eddy currents in the tube wall as the tube being inspected is passed through the coil form. When the flow of these currents is interrupted by a discontinuity, a sma11 magnetic field is produced. This field is sensed by one or more probe coils, depending upon the size of the discontinuity. These coils are sampled at a high rate. Thus, advantage is taken of the small inspection area of the probe coils. The number of coils sampled at one time, and their positions, depend upon the type and size of tube being inspected and the desired defect detection level.

The clock in the prototype system operates at 10,000 pulses per second. Therefore, the optimum read-out device would be a fast-response alarm circuit. Such a circuit would be able to respond to signals at each sampling time and would not be influenced by the preceding or succeeding signals. In our particular case, it is highly desirable to have a permanent record so we use a conventional strip chart recorder. The signal-to-tube noise ratio is degraded somewhat by using this recorder but not to an objectionable degree. Since the recorder cannot respond at the high sampling rate, the recording is actually an average reading of all the probe coils.

For the 0.230 in. OD tubing test, two probe coils (that were physically 180 degrees apart) were sampled at a time. These coils were electrically connected so that the signals that are caused by tube eccentricity cancel. 
In the initial setup, the calibration standard is inserted into the bore of the coil form. With the clock off, the counter is reset to zero by pushing the "Reset" button. At this count, Signal Gate 1 is on and only the signals from the two coils connected to this gate are coupled to the tester. The residual coil voltage is then nulled, using the Balance Circuit 1 controls. An oscilloscope, connected to the nondifferentiated $X$ and $Y$ tester output terminals, is used to determine the null condition. The clock is then manually singlepulsed, which causes the counter to count to the next number. Signal Gate 2 is then on and only the coils connected to this gate are coupled to the tester. The nulling procedure for these coils is performed. This procedure is repeated until a11 of the coils have been balanced. The clock is then turned on and the conventional procedure of phasing the tube wobble signal into the horizontal (X) channel is then performed. The system is then ready for operation.

\section{TEST RESULTS}

Figure 6 shows the cross section of the calibration standard used to obtain comparison runs of both the encircling coil and hybrid coil techniques. It is 316 stainless stee 1 and has a 0.230 in. OD with a 0.015 in. wall. Twelve electricdischarge-machined notches of various sizes serve as artificial defects.

Figure 7 shows the results obtained using the conventional encircling coil technique. This method utilized two differentially connected encircling coils, each $30 \mathrm{mils}$ wide, spaced $30 \mathrm{mils}$ apart. The results were actually fairly good. Out of a total of 12 notches, 11 were detected. Notch 5 was completely masked by a background signal of undetermined origin. It is quite likely that this signal was caused by a very slight dimensional change that encompassed a rather 


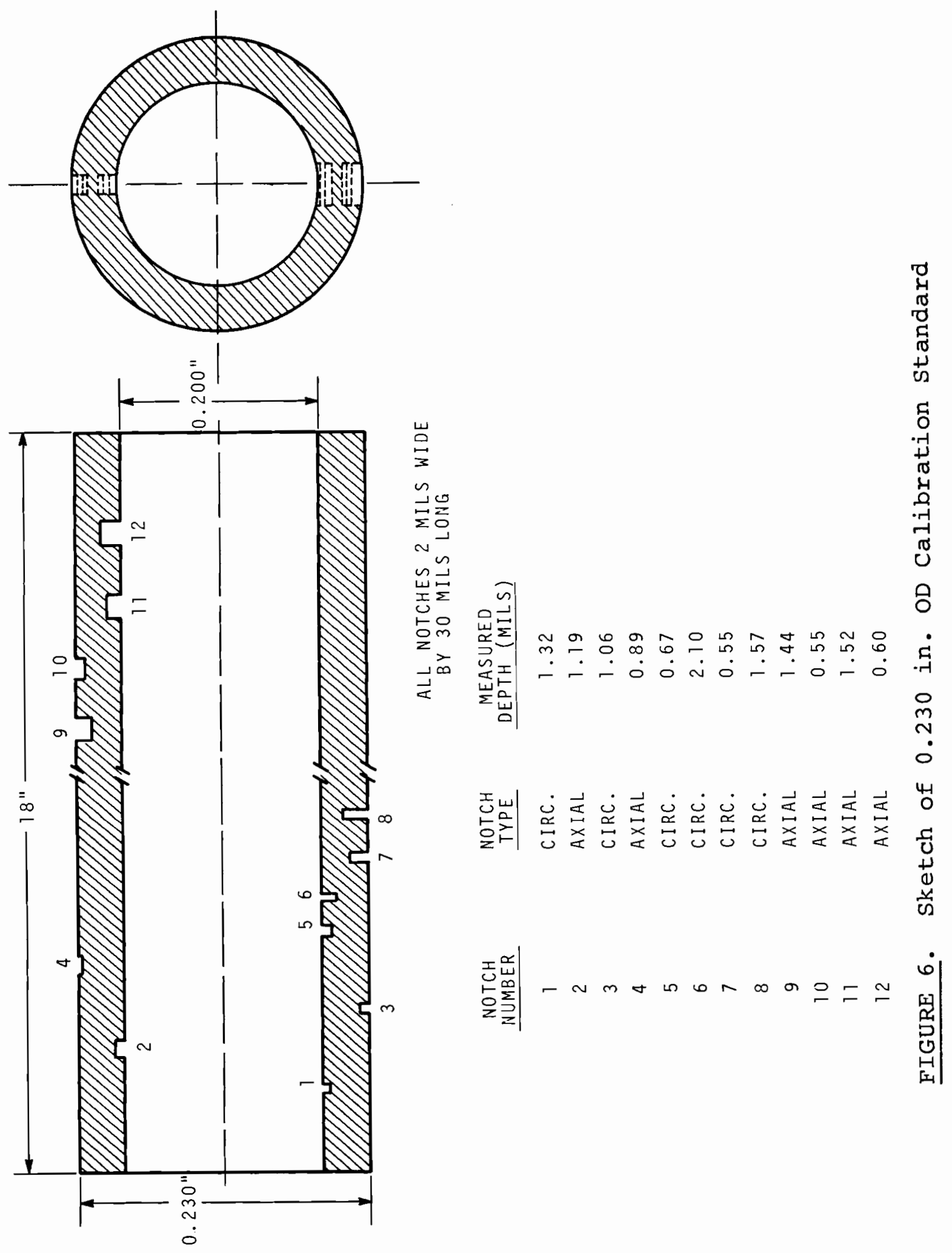


large portion of the tube circumference. The encircling coil therefore effectively integrated the signals from this anomaly and produced an indication out of proportion to its depth.

The indication designated A near Notch 10 was also probably due to a similar anomaly.

Figure 8 shows the results obtained using the sequentially sampled hybrid coil. A total of 6 probe coils, two sets of 3 coils physically $180^{\circ}$ apart, were sampled at one time. Since the total number of probe coils in this coil form was 18 , three sets of 6 coils were used.

With a clock rate of 10,000 times per second, each set of 6 coils was sampled 3,333 times per second.

The sampled hybrid coil technique detected all 12 notches and with a considerably better signa1-to-tube ratio. This technique discriminated against the anomaly which had masked the signal from Notch 5 using the encircling method. The indication at point A was also reduced in magnitude. These results substantiate the previous statements that these two indications were from anomalies which we re shallow in depth but which encompassed a fairly large area.

One would expect the advantages of the hybrid coil system to be even more pronounced when used on larger diameter tubing. To verify this, some comparative data were obtained from a $0.563 \mathrm{in.} O D$ by $0.032 \mathrm{in}$. wall Zircaloy tube (see Figures 9 and 10). This tube contained electric-discharge-machined notches 2 mils wide by $62 \mathrm{mils}$ long, of depths and orientations as shown in Figure 10 .

The encircling coil method did not detect any of the notches (see Figure 9). The coil configuration for this test consisted of two differentially connected encircling coils, each 50 mils wide and spaced $30 \mathrm{mils}$ apart. 
BNWL- 1355
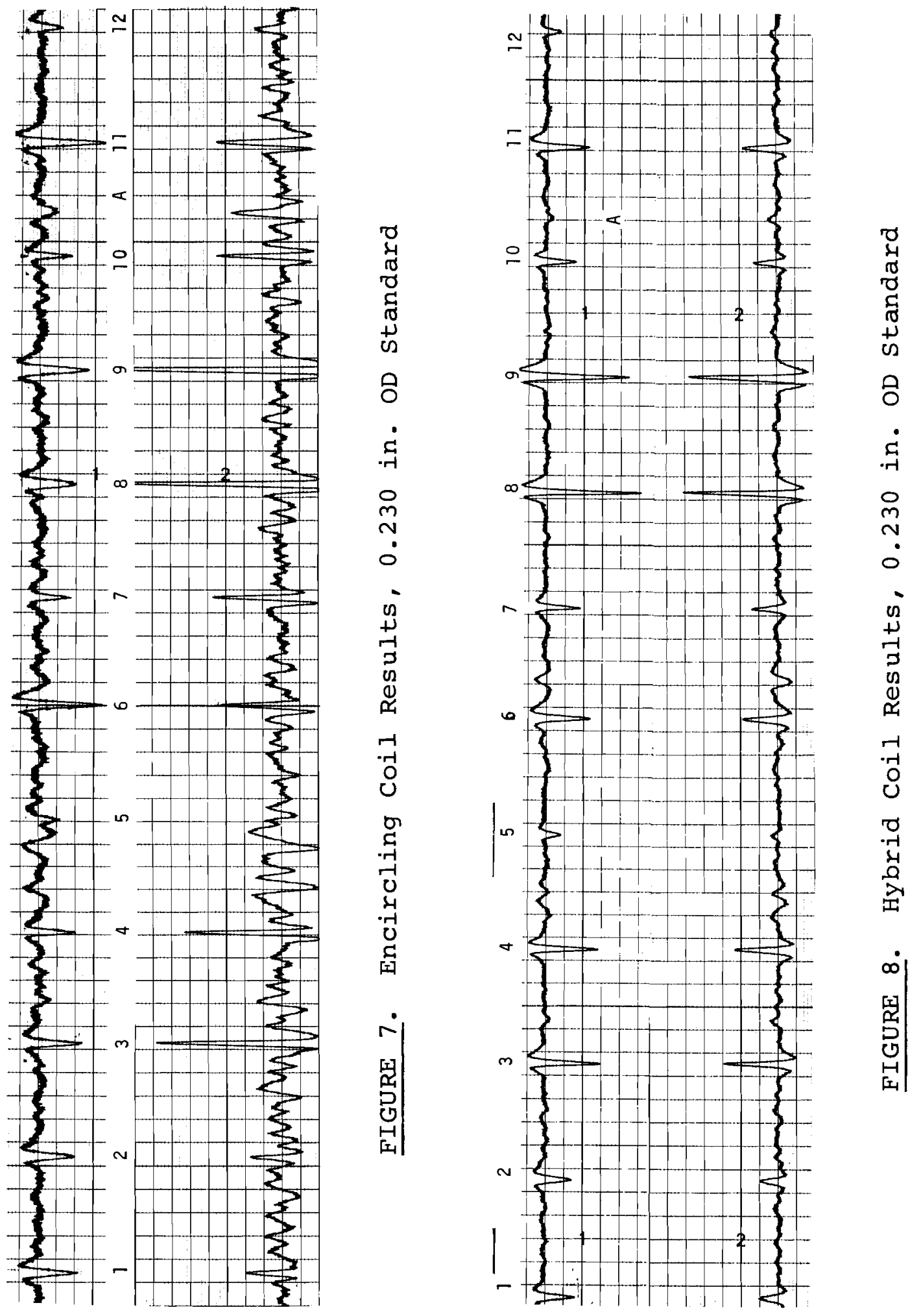
BNWL- 1355

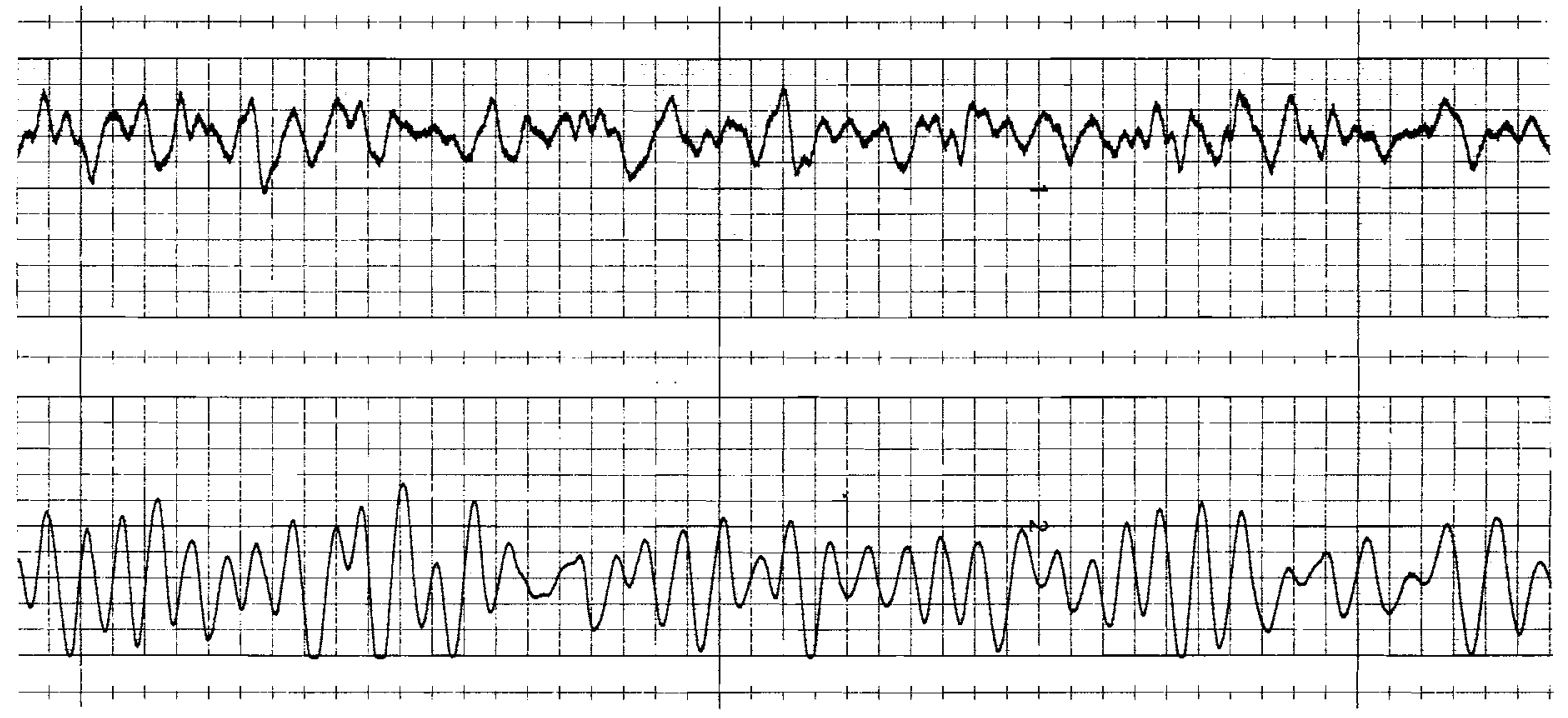

FIGURE 9. Encircling Coil Results, 0.563 in. OD Standard

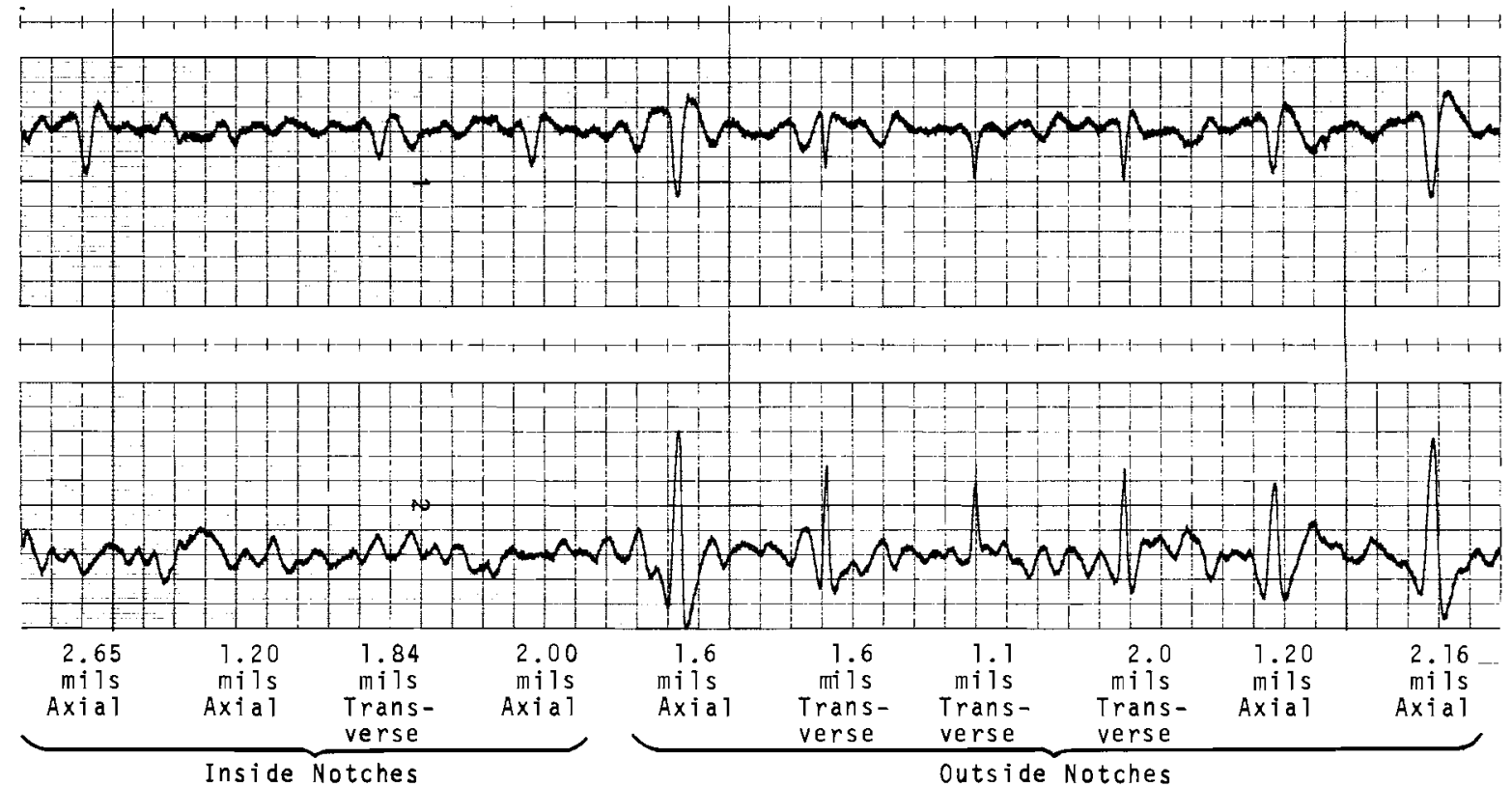

FIGURE 10. Hybrid Coil Results, 0.563 in. OD Standard 
The data shown in Figure 10, demonstrating the hybrid coil system, was obtained by using on $1 y$ a portion of the total required probe coils. For $100 \%$ circumferential coverage, 28 probe coils each $58 \mathrm{mils}$ in diameter would be required. However, for demonstration purposes on $1 y$ two we re used. These were physically $180^{\circ}$ apart and were sampled at a clock rate of 10,000 times per second. The two encircling coils were 50 mils wide, spaced $80 \mathrm{mils}$ apart.

The results show that all of the outside notches were easily detected. Inside notches greater than approximately 2.5 mils were detected. Possibly, the detection capabilities to inside defects could be improved by optimizing coil sizes. Nevertheless, the hybrid coil results are many magnitudes better than the encircling coil results.

\section{ACKNOWLEDGEMENTS}

The author wishes to express his appreciation to E. F. Perrizo for his many contributions. This work was funded by FFTF Fuels Quality Assurance Section of Battelle-Northwest.

\section{REFERENCES}

1. J.Ryden, Jr. Nondestructive Testing of Small Diameter Stainless Steel Fuel Clad Tubing, BNWL-SA-2275. BattelieNorthwest, Richland, Washington, February 1969.

2. H. L. Libby. An Improved Eddy Current Tubing Test, HW-81780. Available from Clearinghouse for Federal Scientific and Technical Information, Springfield, Virginia 22151. May 7, 1964. 


\section{DISTRIBUTION}

No. of

Copies

OFFSITE

1

212

ONSITE

1

AEC Chicago Patent Group

R. K. Sharp (Richland)

$1 \quad$ AEC Richland Operations Office

C. L. Robinson

Batte11e Memorial Institute

2

RDT Assistant Director for Pacific Northwest Programs

61

AEC Chicago Patent Group

G. H. Lee

AEC Division of Technical Information Extension UC - 37

Batte 11 e-Northwest

E. R. Astley

R. E. Bardsley

C. A. Burgess

A. C. Callen

T. T. Claudson

R. M. Crawford

G. J. Dau

R. J . Lobsinger

H. N. Pedersen

H. G. Powers

J. Ryden, Jr. (25)

C. B. Shaw

J. C. Spanner

W. F. Stevenson

J. C. Tverberg (15)

J. B. Vetrano

Technical Information Files

Technical Publications (2) 